\title{
RHSS

\section{Vocación por el hacer y el ser en las profesiones del sector salud ${ }^{ \pm}$}

\author{
Vocation for doing and being in the health care sector
}

Héctor Mauricio Mazo Álvarez ${ }^{1^{*}}$, Magíster, Doctor en Filosofía.

${ }^{1}$ Docente investigador. Facultad de Medicina, Corporación Universitaria Remington, Medellín-Colombia.

(Aceptado: 17 de noviembre de 2014)

\section{Resumen}

Todos en algún momento hemos escuchado que otras personas o incluso nosotros mismos utilizamos la palabra vocación, decimos que tal sacerdote tiene vocación, que ese ingeniero tiene vocación incluso utilizamos esta palabra para designar no solo roles u oficios sino incluso rasgos del carácter, como cuando decimos que esa persona tiene vocación de sumiso. La palabra vocación proviene del latín vocare o vocari que significa llamado o acción de llamar, se entiende como llamado hacia un determinado fin o destino. Ambos verbos en infinitivo se relacionan con el sustantivo vox, equivalente al castellano voz. Podríamos decir entonces que la vocación es el llamado que siente cada uno a cumplir con un destino. Pero este destino lo que nos señala es el camino que vamos a seguir durante nuestra existencia.

En el paso por la vida los hombres podrán realizar muchas actividades y muchos oficios pero muy pocos son realizados con vocación. La sociedad contemporánea ha privilegiado otros factores por encima del vocacional cuando se trata de elegir una ocupación, de este modo, la remuneración, la estimación social o incluso la moda, son factores más importantes cuando se trata de elegir una carrera, lamentablemente estos nos ha llevado a la proliferación de personas que se desempeñan en oficios o profesiones por los cuales no sienten la más mínima vocación, llevando esta situación a que su desempeño sea absolutamente instrumental y técnico, pero en el sector de la salud si se hace fundamental que las personas que allí laboran se desempeñen no solo con un vasto conocimiento de su profesión, sino con una inquebrantable vocación por su quehacer, en otras palabras, con un amor infinito por lo que hacen.

Palabras clave: desempeño profesional, profesión, sector salud, vocación.

${ }^{\Perp}$ Para citar este artículo: Mazo Álvarez HM. Vocación por el hacer y el ser en las profesiones del sector salud. RHS. Revista. Humanismo. Soc, Volumen 2 (2): 52-64.

${ }^{\star}$ Autor para correspondencia: Héctor Mauricio Mazo. Corporación Universitaria Remington. Calle 51 No 51-27. Edificio Remington. Correo electrónico: hector.mazo@unremington.edu.co.

Revista. Humanismo.Soc. 2014; Volumen 2 (2): 52-64. 


\begin{abstract}
Everyone, at some point, has heard or used the word "vocation"; e.g., people say, "that priest has a vocation", "that engineer has vocation". We even use that word to denote not only roles or jobs but also character traits; as when we say "that person has a vocation of submissive". The word vocation comes from the Latin meaning vocare or vocari, which implies action or calling; it means "call to a particular purpose or commitment". Both verbs in infinitive relate to substantive vox, equivalent to voice in Spanish. We could say that vocation is the call that someone feels to meet his/ her destiny, which points to a path we will follow during our existence. People perform many activities and occupations during life, but very few are the result of a vocation. Contemporary society has favored other factors over vocation when it comes to choosing a job or occupation; thus, payment, esteem, or even social tendencies become the most important factors when it comes to choosing a career. Unfortunately, this has lead to the proliferation of people working in jobs or occupations for which they do not feel the slightest vocation, only performing it at an instrumental or technical level. It is essential for people working in the health care sector to not only have great knowledge of their profession but also a firm vocation; in other words, infinite love for what they do.
\end{abstract}

Key words: calling, health care sector, professional performance, profession.

\title{
Un ejercicio de contextualización
}

De todos es conocido que el oficio que desempeñaba José, padre de Jesús, era el de carpintero. Oficios muchas veces aprendidos en el seno familiar, un padre que conoce la técnica y los secretos de su trabajo y los trasmite a su descendencia. Para la época de José se era carpintero, pescador, artesano, comerciante, pastor entre otros, la oferta laboral no era muy amplia, por ende, las posibilidades de escoger eran muy limitadas. En el mundo medieval aparecen otras necesidades y otros oficios, tenemos los copistas, los monjes de las abadías entre otros, pero a estos nuevos oficios hay que sumar la aparición de nuevas instituciones como las universidades y por ende las profesiones. La formación ya no solo es un asunto técnico es un asunto académico y conceptual. Elegir un oficio ya no solo es un asunto familiar o de habilidad técnica, sino de tiempo para la formación teórica. Y en el mundo contemporáneo seguimos manteniendo la estructura de formación universitaria y sumada la proliferación de una oferta casi inagotable de posibilidades laborales.

No obstante aunque seguimos hablando de oficios, profesiones y artes cada uno de ellos se realiza satisfactoriamente si se desempeña con vocación.
Cuando elegimos, una profesión como es el caso de las profesiones del sector salud, estamos eligiendo no sólo una profesión y es que no sólo es una actividad, bien podríamos decir que es, tal como lo señala González Vila: "un estado y estilo de vida" cada profesión trae consigo un estilo de vida, los deportistas de alto rendimiento tendrán que someterse una disciplina de entrenamientos y dietas para poder cumplir con sus propósitos; el sacerdote realiza unos votos que son: obediencia, castidad y pobreza; las personas que laboran en el sector salud también adquieren unos estilos de vida, trabajar por la salud implica muchas veces el contacto con la enfermedad y por supuesto con la persona enferma, aceptar al ser humano incluso en condición de su mayor vulnerabilidad, a no sentir asco y repudio por las manifestaciones de dicha enfermedad, a capacitarse durante toda la vida entendiendo que los profesionales de salud ejercen unas profesiones determinadas pero, que su oficio como el arte siempre se puede hacer mejor y que la ética en el quehacer, el respeto y la dignidad del paciente están por encima de cualquier beneficio económico.

\footnotetext{
${ }^{1}$ González Vila, Teófilo. Vocación, profesión y profesionalidad. En: acontecimiento: Órgano de expresión del Instituto Emmanuel Munier, No 54, 2000, p, 49.
} 
De este modo los estilos de vida están íntimamente relacionados con el sentido de la existencia. Podemos realizar muchas actividades, por ejemplo, podemos conducir un vehículo pero nuestra vocación no es la de chofer, podemos practicar algún deporte pero nuestra vocación no es la de deportista, podemos acompañar a alguien en su proceso de enfermedad pero nuestra vocación no ser la de trabajador de la salud; los estilos de vida que se le imponen al trabajador de la salud son altamente demandantes, exigen una capacidad de entrega y sacrificio que en pocas ocasiones se observa en otras profesiones. Estas son campos laborales que demandan una alta vocación ya que muchas personas lo pueden hacer pero son pocas las que lo pueden hacer bien, para algunas personas trabajar en el sector salud puede ser el resultado de una férrea voluntad pero sin formación o de una formación pero sin vocación, en el primer caso tenemos personas con ganas pero sin pericia y en el segundo caso tenemos al trabajador que es automatizado en su quehacer.

De esta forma la actividad realizada con vocación se convierte en la situación ideal, ya que tenemos una persona que se capacita en lo que le gusta, recibe la formación adecuada para adquirir los conocimientos necesarios y finalmente pueda hacer lo que le apasiona. Casas así lo señala: "La vocación no es una actividad más, es el ejercicio de nuestra vida, el ámbito de gran parte de nuestra realización personal y social"2. Muchas personas hoy en día escogen una profesión o un oficio en razón a las habilidades que poseen, si tengo estas competencias lo mejor que puedo hacer es dedicarme a algún oficio que requiera de dichas competencias, en otras palabras, si soy bueno para las matemáticas, entonces, puedo ser ingeniero pero si no tengo habilidad entonces mi oficio no deberá tener proximidad con dicho saber. Tomamos decisiones en razón a las habilidades o dificultades que poseemos en el campo de los saberes y disciplinas de nuestra formación básica. Tener en cuenta estas condiciones es importante, pero no puede ser determinante en nuestras decisiones. El hecho que tenga talento para expresar lo que pienso y lo que conozco no quiere decir que tenga que ser docente. No es solamente para aquello que soy bueno, básicamente, la elección de una profesión debería comenzar con el cuestionamiento: ¿qué me hace feliz? Si pienso que dicha elección no es solo determinar un oficio, sino un estilo de vida, este tendrá, por lo menos, que hacerme feliz en su realización.

Del mismo modo hoy nos hemos dejado llevar por un marcado sentido material de las cosas, las prácticas adquieren legitimidad en la medida que son útiles para quien las realiza y representan una ganancia inmediata en términos económicos. Escogemos las profesiones $\mathrm{u}$ oficios que representan una buena oportunidad en términos económicos. Incluso hemos llegado el extremo de dejar de lado los cuestionamientos éticos y morales frente a determinadas prácticas porque generan muy buenas ganancias económicas. La riqueza no es un bien despreciable en sí mismo, son los medios que seleccionamos para llegar a dicho bien. Nuestra ansia de lucro no podrá estar jamás por encima de las convicciones morales y éticas que cada uno tiene. Gonzales Vila así lo señala: "El primero y más alto plano en el que puede considerarse la vocación es precisamente éste, transcendente, antropológico, metafísico, religioso, moral, del destino y sentido de la existencia." ${ }^{3}$ Esto quiere decir que nuestra vocación tiene como limites naturales lo que nuestra sociedad nos permite en términos de lo legal y lo ético. Una persona puede cometer hechos ilegales, pero no podríamos hablar de una vocación hacia la ilegalidad.

Una característica de la vocación es que aquellas personas que la poseen son capaces de soportar las circunstancias más adversas solo por el amor que sienten por aquello que hacen, esta característica marca una condición muy particular de los seres humanos, no sólo hacemos las cosas, podemos hacerlas bien, nos preocupamos por hacerlas bien. Y esta condición muestra una de las principales características de nuestra naturaleza, no solo es un hecho biológico donde estamos determinados por nuestra naturaleza biológica, sino que somos seres sociales y que nuestra otra condición es la der ser seres culturales. Y es dicha cultura la que marca las necesidades y las formas de

\footnotetext{
${ }^{2}$ Casas Pérez, María de la Luz. Conocer y amar: vocación médica. En: cuadernos de bioética. Vol 9. No, 34, 1998/2 p, 336.

${ }^{3}$ González Vila, Teófilo. Vocación, profesión y profesionalidad. En: acontecimiento: Órgano de expresión del Instituto Emmanuel Munier, No 54, 2000, p, 49.
} 
respuesta idóneas a dichas necesidades. en muchas situaciones las necesidades son grandes y la capacidad de respuesta muy limitada, por ende quien responde muchas veces lo hace desde no solo desde los recursos sino desde su propia vocación.

De otro lado podríamos decir que la vida se constituye como vida, en la medida que vamos viviendo, al ser humano no solo se le imponen metas desde su naturaleza biológica además debe cumplir con propósitos que se le imponen desde la dimensión social y estos a su vez le dan sentido a la existencia. Ese llamado a cumplir con esas metas o propósitos es lo que llamamos vocación. Será el filósofo español Ortega quien nos dirá lo siguiente: "No hay vida sin vocación, sin llamada íntima. La vocación procede del resorte vital, y de ella nace, a su vez, aquel proyecto de sí mismo, que en todo instante es nuestra vida"4

No solo vivimos por lo que hacemos, nuestra vida cobra sentido por aquello que hacemos, como lo señaló Ortega y Gasset, la enfermera no solo vive de su profesión, es su vocación la que dota de sentido su vida. Los seres humanos somos capaces de proyectarnos en aquello que hacemos, esto quiere decir que en cada acto humano se puede ver nuestro mejores valores y virtudes pero del mismo modo podemos ver nuestros peores defectos. Farrari Nieto así lo indica a propósito de la obra del filósofo español: "En Ortega la vida no tiene un sentido biológico, sino biográfico: la lucha del hombre con su entorno, un dinamismo dramático entre yo y el mundo; no dejarse ser, como cualquier otro animal. La vida es drama, explica, porque consiste en tener cada uno que ir haciéndose a sí mismo, en perpetua tensión"5

Ese llamado implica una lucha por ser lo que se quiere ser y no lo que me toca ser, hay personas que hacen caso omiso a su vocación porque les toco ser algo distinto a lo que querían ser, pero muchas otras luchan para que su destino marche en la misma vía de su vocación, tal es el caso de Florence Nightingale, quien durante la batalla de Crimea la brindo cuidados de enfermería a los soldados británicos heridos, además resolviendo problemas del entorno como: la falta de higiene y la suciedad. Esto generó reconocimiento a su labor pero en algunos sectores rechazo. Como lo señala Tomey: "el trabajo de Nightingale para mejorar estas condiciones deplorables la convirtió en una persona muy popular y querida entre los soldados, pero los médicos y los oficiales militares no apoyaban sus métodos"6. De tal suerte que este tipo de personas construyen su porvenir muchas veces con pequeños actos desprovistos de sentido para la mayoría de las personas, tal es el caso de los procesos de formación a nivel universitario, donde los estudiantes deben cursar asignaturas a las cuales quizás no le encuentren mucho significado o simplemente no sean de su agrado. Es la capacidad de proyectar una vida a pesar del presente. Será Marías quien en este sentido nos comparta la siguiente reflexión: "es proyectar, imaginar, anticipar, es seguir proyectando, imaginando, anticipando, soy inexorablemente futurizo, orientado al futuro, remitido a él"7

De la misma forma, el futuro, aunque indescifrable en su totalidad, me permite construir elementos que me den cierta noción de arraigo en el presente, elegimos porque nos proyectamos en el futuro, nos capacitamos porque nos vemos en determinado lugar y esto lo podemos hacer porque somos capaces de soñar, imaginar y desear; en otras palabras porque somos seres simbólicos, porque no estamos determinados a un significado inequívoco de los cosas, sino a la interpretación permanente de los hechos y de la vida. Savater nos dice lo siguiente: "Nuestra estructura biológica responde a programas estrictos, pero no así nuestra capacidad simbólica (de la que dependen

\footnotetext{
${ }^{4}$ Ortega y Gasset, J. el hombre a la defensiva. Obras Completas II, alianza editorial, Madrid, 1983, p, 655 - 656.

${ }^{5}$ Ferrari Nieto, Enrique. El recorrido de la analogía metafísica del actor en la comprensión de Ortega de la vida como tarea. En: Revista Internacional de Filosofía, vol. XVIII (2013), pp. 319-337

${ }^{6}$ Marriner Tomey, Ann. Raile Alligood, Martha. Modelos y teorías en enfermería. Elsevier Mosby, Madrid, 2007, p, 74

${ }^{7}$ Marias, Julián, Antropología metafísica. Madrid: Revista de Occidente, 1970, p. 299.
}

Revista. Humanismo.Soc. 2014; Volumen 2 (2): 52-64. 
nuestras acciones). Digamos que los seres humanos estamos programados en cuanto "seres", pero no en cuanto humanos"s.

De este modo las acciones de los hombres muchas veces están más allá de la dimensión biológica como causal de explicación. En el hermoso mito griego de Prometeo la naturaleza humana está directamente relacionada con el robo del fuego a Hefestos, el fuego es por excelencia el símbolo de la cultura. Nuestra naturaleza, como ya la señalábamos es social y además simbólica. La reproducción sexual, es otro de los ejemplos, es un instinto en todas las especies, pero los seres humanos son capaces de convertir ese acto en un símbolo que tiene significado preciso dentro de una época y una cultura, también dependerá de las personas, su formación y estilo de vida. Savater al respecto nos dice:

Los animales viven sin proponérselo, como es debido; los humanos debemos proponernos estilos y planes de vida para poder vivir. El hombre necesita un símbolo práctico de lo que es y hace para poder ser y hacer. Por lo común, ese símbolo práctico no es monoplaza ni privado sino que lo compartimos con muchos otros, lo recibimos de quienes se nos asemejan y lo transmitimos a quienes queremos que se nos asemejen: cada símbolo práctico de la vida deseable es un vínculo social, una "religión" (de religare, establecer una unión o ligamento interpersonal codificado de carácter virtual). ${ }^{9}$

Esta condición de seres simbólicos nos lleva al campo de la elección, elegimos como vivimos o por lo menos deberíamos de hacerlo, los seres humanos cuando tomamos una decisión lo hacemos en razón de nuestra naturaleza biológica y de nuestra naturaleza social. Y en cada una de esas decisiones se juega no solo una posibilidad entre una infinidad de posibilidades, sino que nos jugamos también nuestra condición de seres éticos y morales. No solo tenemos la posibilidad de elegir, sino la responsabilidad de elegir bien.

\section{Acercamiento al concepto de vocación}

Podemos entender la vocación como un llamado, sin embargo debemos aclarar que no todo llamado es vocacional. Yo puedo sentir el llamado que me dice que debo cuidar de los animales, pero puedo acudir a este llamado desde un ejercicio más cercano al voluntariado, puedes sentir el llamado a la música pero esto no es condición para que te conviertas en un músico de profesión. Expresado de otro modo podemos tener afinidad por ciertos temas, problemáticas u profesiones pero no son necesariamente una vocación, esta va más allá del simple interés o sensibilidad, en la vocación lo que estamos proyectando es nuestro propio ser. González Vila así lo indica: "En su sentido más propio y elevado, marcado por sus originarias connotaciones religiosas y morales, la vocación se entiende referida a actividades de especial excelencia intrínseca y a motivaciones e intenciones moralmente elevadas, desinteresadas." ${ }^{10}$ Quizás este aspecto sea uno de los más importantes en este tema, este llamado lleva implícito un alto sentido de virtud en sí mismo, ya que quien acude a dicho llamado, encuentra en esta actividad la expresión más sublime de sus mejores cualidades, por citar un ejemplo, el artista encuentra en su arte la forma más bella de expresar su interioridad, Sponville al respecto dice: "el arte es un hecho especifico del hombre"11 solo el hombre puede expresarse por medio del arte.

Podríamos comenzar diciendo del arte que es todo aquello que se considere una creación humana, el ebanista crea con la madera, el escultor crea con la arcilla, el escritor con su pluma; pero la definición va mucho más allá, ya que no solo es el hecho de crear, es expresar algo con aquello que se ha creado. La pieza de madera no solo es el objeto es la expresión del artista, la obra literaria no es solo una pieza es la expresión de la sensibilidad del artista, quizás para muchos artistas sus objetos de arte solo sean eso, objetos. En cualquier expresión humana si observamos la expresión de una

\footnotetext{
${ }^{8}$ Savater, Fernando. El valor de elegir. Barcelona: Ariel, 2003, p, 13.

${ }^{9}$ Savater, Fernando. El valor de elegir. Barcelona: Ariel, 2003, p, 13.

${ }^{10}$ González Vila, Teófilo. Vocación, profesión y profesionalidad. En: acontecimiento, p, 49.

${ }^{11}$ Sponville, André Comte. Invitación a la filosofía. P, 115
} 
idea, de una percepción, de un sentimiento lo que encontramos es una expresión artística. Podríamos en este punto decir que una verdadera vocación se expresa como el arte. Martínez así lo presenta: "es la inclinación natural de una persona por un arte, una profesión o un determinado género de vida"12

El profesional de ciencias de la salud no solo debe encontrar en su profesión una ocupación o un oficio, no es sólo un trabajo que representa una remuneración, los médicos, las enfermeras, los odontólogos, los psicólogos y demás profesionales de la salud deberán encontrar en su profesión un arte que les permita en cada acción expresar sus más altos ideales y valores. Solo en ese sentido se trasciende la dimensión técnica. Uno de los señalamientos que se hace hoy en día a los profesionales de salud, es lo deshumanizado que se ha vuelto la relación con los pacientes. El médico no solo debe saber leer los signos e interpretar los síntomas, debe hacerlo con una serie de virtudes o valores que solo aparecen si ese ejercicio esta antecedido por una verdadera vocación. Algunas personas sin vocación pueden apelar a la cortesía pero esta no alcanza ya que es apariencia de virtud pero no es virtud en sí misma.

De otro lado nos encontramos con una situación a la cual debemos prestar toda la atención en el mundo contemporáneo. A nuestros estudiantes los hemos dejado solos en la difícil tarea de identificar su verdadera vocación, los resultados no podrían ser más desoladores, un alto porcentaje de estos estudiantes se equivocan cuando eligen una carrera para ingresar a la universidad y muchos de ellos a pesar del error terminan graduándose de dichas carreras. En términos educativos el acompañamiento muchas veces se reduce a unas pruebas psicométricas que miden las aptitudes $\mathrm{y}$ actitudes que tiene el estudiante y de acuerdo a esto con que perfil en términos profesionales se acomoda más. Sin tener en cuenta que muchas veces el destino de los hombres no está marcado por aquello que se nos presenta como viable sino por aquello que parece más difícil frente a nuestros ojos.
González Vila nos dice al respecto: “Con la idea más generalizada de vocación se vinculan las de aptitudaptitudes, inclinación, afición y gusto, por más que haya casos en los que el «llamado» no encuentre precisamente grata la tarea para la que se le reclama"13 no podemos dejar que se nos engañe en relación a nuestras aptitudes, el hecho de ser bueno para las matemáticas no quiere decir que tenga que ser ingeniero, como ya lo señalabamos. Mujica al respecto dice:

Estar dotado para algo quiere decir que nuestra naturaleza nos lleva a hacer algo a gusto. Por regla general tendemos a aquello a lo que por naturaleza estamos dotados, y la actividad correspondiente nos produce satisfacción. Pero la inclinación implica una especial estimación de lo que se hace. Puede suceder que no se estime especialmente aquello para lo que se está dotado, y que en cambio estimemos mucho algo para lo que no estamos dotados en esa misma medida. La estimación produce alegría en la actividad, y la alegría es un incremento de la fuerza (...) Quien considera el propio trabajo sólo como fuente de ganancia o como modo de ocupar el tiempo, lo desarrollará de manera diversa a quien lo considera una verdadera vocación a la que se siente llamado".14

En este punto sería fundamental un cambio de mirada frente al acompañamiento que hacemos a los estudiantes en sus primeros años de vida escolar, muchas veces las facilidades crean zonas de confort de las cuales no queremos salir y termina siendo más perjudicial para el propio estudiante, debemos desarrollar una mayor tolerancia a los procesos y tiempos de aprendizaje, quizás en forma latente se encuentra más de una verdadera vocación, que los docentes o el sistema educativo leen en los estudiantes como un simple acto terquedad, y se escucha decir por parte del educador -no tienes las habilidades para este campo de acción. Los ejemplos de esta situación son innumerables, al escritor argentino Ernesto Sabato no le recibieron la novela del túnel, porque un científico no podía ser escritor. Zaragueta nos dice al respecto:

\footnotetext{
${ }^{12}$ Martínez Casanovas, Carlos. La vocación de ser médico. En: revista de la semg, No. 64, 2004, p, 318

${ }^{13}$ González Vila, Teófilo. Vocación, profesión y profesionalidad. En: acontecimiento, p, 49.

${ }^{14}$ Mujica, Jorge Enrique. La vocación de la mujer según Edith Stein.
} 
El «sentirse llamado» es algo más que un mero sentimiento, en el significado de «gusto» o «afición» por una cosa por ventura pasivamente recibida; es, en todo caso, un sentimiento dinámico y fecundo que más bien merece el nombre de inclinación o tendencia, en la que nuestra propia actividad y aptitud nos aparecen como eficazmente dominadas por la conciencia, no solo de la posibilidad, sino de la conveniencia y aún de la necesidad de realizar un cometido determinado ${ }^{15}$

La mayoría de las personas sentimos un gusto, que podríamos calificar de natural, por servir a los demás. Algunos disfrutan de acompañar a una persona enferma un momento, otros podrán sentir una gran satisfacción cuando ayudan a una persona en una situación difícil, pero no necesariamente este marca una vocación, algunas veces este tipo de sentimientos están amparados en necesidades efímeras como podría ser el reconocimiento y la satisfacción con nosotros mismos, esto quiere decir que cuando encontramos el reconocimiento o nos encontramos satisfechos desaparece la necesidad de ayudar. Estas motivaciones aunque son valederas en ellas se encierra algo de egoísmo. En otras palabras es importante el reconocimiento y la satisfacción propia pero no pueden ser el punto de partida de una verdadera vocación. Al respecto dice Gracia: La vocación no es un propósito, ni un proyecto. Es algo previo a todo eso. Es algo que se nos impone desde dentro de nosotros mismos con fuerza irresistible, de modo que si no lo seguimos frustramos nuestra vida. ${ }^{16}$

La vocación, de este modo, es el llamado a cumplir una necesidad pero no es el cumplimiento; el cumplimiento es la profesión, muchas personas creen que son buenas porque cumplen con sus obligaciones. La vocación es un impulso, una urgencia, una necesidad insatisfecha; que lleva a la persona a realizar una serie de labores no por obligación sino por convicción. De este modo la vocación no es solo una habilidad, como ya la habíamos mencionado, no es solo un gusto, sino la convicción que por medio de una profesión cumplimos con una necesidad que nace en lo más profundo de nuestro ser. Pantoja nos trae a propósito la siguiente reflexión: "La vocación le permite al hombre desarrollar sus habilidades, actitudes e intereses y autorrealizarse para alcanzar el éxito y una posición social. Este proceso dinámico orienta al individuo a elegir una profesión $\mathrm{u}$ ocupación, la elección debe ser una decisión personal en la que intervenga la conciencia y la voluntad." ${ }^{17}$ De este modo quien elige una profesión deberá tener en cuenta que en esa elección no solo se juega un asunto laboral tendrá que considerar que en dicha elección también se encuentra la posibilidad de la autorrealización. Una profesión o un oficio deberán procurar en quien las ejerce una forma de realización no solo de su proyecto laboral sino personal.

Pero todo esto parte del conocimiento que tenemos de nosotros mismos, lo increíble es que muchas veces tenemos que esperar a que una prueba me indique para que tengo habilidad, Nietzsche lo plantea de manera magistral: "Nosotros los que conocemos somos desconocidos para nosotros, nosotros mismos somos desconocidos para nosotros mismos: esto tiene un buen fundamento. No nos hemos buscado nunca, ¿cómo iba a suceder que un día nos encontrásemos?"18 La gran realidad es que no nos conocemos. El hombre hoy que es capaz de revelar los enigmas de la ciencia sigue sin conocerse a sí mismo, incluso seguimos sin comprender que conocimiento no es lo mismo que sabiduría, el problema es que pensamos más de lo que sabemos, nosotros valoramos mucho las ideas, los conceptos y en muchas situaciones olvidamos los hechos. Podemos llenar nuestra mente de pensamientos de nosotros mismos, pero estos no dirán más de mí que un lunar sobre la punta de nuestra nariz. Vásquez así lo señala: "La elección vocacional surge del conocimiento que tiene cada persona de sí mismo y de la carrera o profesión así como de la representación que se construye sobre ambos, donde las expectativas

\footnotetext{
${ }^{15}$ Zaragueta, Juan. La vocación profesional. En:

${ }^{16}$ Gracia, Diego. La vocación docente. En: anuario jurídico y económico escurialense. XL, 2007, P, 810.

${ }^{17}$ Pantoja, Cecilia. En torno al concepto de vocación. En: educación y ciencia. Vol. 2, No, 6. P,

${ }^{18}$ Nietzsche, Frederich. La genealogía de la moral.
} 
personales (creencias acerca de la probabilidad de alcanzar una profesión), creadas por la información situacional, juegan también un papel esencial"19

El gran problema que los hombres tienen en estos momentos es que no se conocen, por lo menos en términos volitivos y trascendentes. Y es esta condición factor determinante para que no identifiquen con claridad que es lo quieren hacer con su vida, no en términos de los ideales sociales que se han impuesto sino de la parte más íntima y que obedece a lo vocacional. Lamentablemente esto ha traído como consecuencia que muchas personas hoy no laboran en lo que es su vocación, sino simplemente en lo que pueden encontrar. Ferrari Nieto nos aporta la siguiente idea: "sólo vive de verdad el que vive su vocación. Aunque la mayoría de los hombres desoyen su llamada; y falsifican su vida, se estafan a sí mismos con una falsa trayectoria vital" 20 lo más paradójico es que la vocación es el derecho inalienable de cada individuo para elegir la ocupación -profesión u oficio- que prefiera estudiar y ejercer.

De la misma forma hoy elegimos por moda o por las fuentes de trabajo que nos rodean, y esto es sumamente riesgoso; la moda tiende a desaparecer en poco tiempo y los centros de trabajo -principalmente las fuentes no nacionales, como hemos visto suceder con las grandes multinacionales pueden cerrar o emigrar. Y esta situación no es propia del sector industrial también sucede en la educación, especialmente en la educación universitaria, donde muchas personas hoy no pueden ingresar a este nivel de formación, porque no cuentan con los recursos necesarios para pagar los costos específicamente de las universidades privadas. El acceso a la educación sobre todo en los niveles superiores marca un reto muy grande para la sociedad contemporánea, ya que este tipo de formación ha sido privilegio durante muchos años de las familias más pudientes.
El segundo elemento que queremos trabajar de la vocación lo encontramos en el mundo de los valores socioculturales, las tendencias vocacionales orientan al ser humano hacia una determinada esfera de valores necesarios como marco de referencia y estructuración de la personalidad individual. En una sociedad como la nuestra ciertos oficios cuentan con un muy buen reconocimiento mientras que otros han caído en desgracia, por lo menos en términos de reconocimiento social. A finales del siglo XIX la profesión de telegrafista era de las más deseadas en Europa hoy en día con la llegada de otras modalidades de comunicación fue desapareciendo. El hecho es que en la sociedad contemporánea opera un sentido pragmático a la hora de elegir una profesión. Este pragmatismo como factor de análisis entre otros factores puede ser muy útil, pero como factor único o determinante de elección puede ser muy peligroso. Garza al respecto nos dice: "Con el tiempo he visto que la vocación, que es una actitud subjetiva que nace del gusto íntimo y el interés por ciertas cosas, que produce personas comprometidas física y moralmente con sus profesiones y con la sociedad, ha sido sustituida por una objetividad utilitarista y convenenciera que (des) orienta a los jóvenes a estudiar aquello que les permita mejorar rápidamente su nivel de vida personal."21

Este sentido pragmático de la sociedad ha llevado a que ciertos comportamientos, actitudes o estilos de vida sean calificados de altruistas, esto quiere decir, que es muy loable quien lo hace, pero no puedo pedirle a todas las personas que lo hagan. Cuando se pide un alto sacrificio, se piensa inmediatamente una alta recompensa. Las dificultades para los trabajadores del sector salud están desde el comienzo de su formación, quizás las formaciones que demandan mayor esfuerzo y disciplina sean las de la salud. Comenzando que el estudiante de medicina es que el más tiempo invierte en su formación de pregrado y son los estudiantes que más dificultades tienen para acceder a su formación de posgrado. Si seguimos esta relación a un gran nivel de

\footnotetext{
${ }^{19}$ Vásquez Alonso, Ángel; Manassero Mas, María Antonia. La vocación científica y tecnológica: predictores actitudinales significativos. En: Rev. Eureka Enseñ. Divul. Cien., 2009, 6(2), pp. 214.

${ }^{20}$ Ferrari Nieto, Enrique. Circunstancia y vocación: apuntes de ortega para una biografía. En: anuario filosófico, XLII, 2009, P, 607.

${ }^{21}$ Garza Almanza, Victoriano. Vocación profesional. En: cultura científica y tecnológica. Enero- febrero, 2007, año, 4. No, 18. P, 44.
} 
dificultad debería seguir una gran remuneración, en este caso, hablamos de la parte económica, pero nos damos cuenta que en la realidad no es así, hay muchas otras profesiones que generan mayor rentabilidad económica con un menor esfuerzo por parte del profesional.

Paradójicamente las profesiones del sector de la salud siguen siendo muy populares en nuestros días, un gran número de estudiantes se quieren formar en dicho sector, específicamente en medicina, esta ha sido una profesión con un alto reconocimiento social, pero con unas condiciones sociales, económicas y jurídicas que han cambiado mucho en los últimos años. El esfuerzo del profesional de salud, es cada vez mayor, pero el reconocimiento es cada vez menos notorio. Por consiguiente si el reconocimiento no siempre es económico, ni social entonces por lo menos deberá ser vocacional. Haldane nos dice: "El ser humano en busca de sentido no lo encontrará con mayor facilidad si renuncia a los modelos del pasado que si los adopta y se adapta a ellos. Esas tradiciones son formas organizadas de trabajo y los seres humanos como agentes creativos tienen mayores posibilidades de descubrir a la vez el sentido y la satisfacción dentro de ellas." 22

En consecuencia podríamos decir que la vocación se entiende como el llamado que siente cada persona, pero ese llamado va más allá de un simple gusto o afición, es aquello que debemos hacer, pero no por obligación, sino por la convicción que en esa actividad damos lo mejor de nosotros, que en ese hacer expresamos lo mejor de nuestras cualidades morales marcando un estilo de vida que nos acerca a una vida más plena y feliz.

\section{Vocación vs profesión}

Tradicionalmente hemos entendido por oficio una ocupación habitual o la profesión de algún arte mecánica. El término suele utilizarse para hacer referencia a aquella actividad laboral que no requiere de estudios formales. Un pintor muy seguramente no tendrá que asistir a una institución para formarse como pintor, un carpintero podrá aprender de su oficio viendo a otros carpinteros, en estos oficios también podríamos esperar que se hicieran con vocación, aunque no es exigible, ya que podríamos tener a ese mismo carpintero que conoce su oficio, pero lo realiza sin vocación. Pero algunas otras actividades si requieren de una formación y estas son a las que llamamos profesiones.

Hoy podríamos decir que muchas de las actividades que realizamos tienen como exigencia cierto nivel de formación. Dependiendo del tiempo y propósitos de formación a nivel superior hablamos de formación profesional, tecnológica y técnica. Pero es de nuestro interés básicamente la formación a nivel profesional, que se caracteriza por realizarse en instituciones educativas específicas (Universidades y fundaciones universitarias) y con un perfil profesional claramente definido. Estos profesionales deben ser seres humanos que no solo sepan el hacer de forma instrumental, sino el por qué y el para qué de lo que están haciendo. Es trascender la dimensión del poder hacer a la del saber hacer. González Vila así lo señala: "La profesionalidad es exigible; la vocación, no. Puede darse profesionalidad sin vocación, y vocación, al menos inicial, sin profesionalidad. Pero no habrá verdadera vocación si de ella no surge la exigencia de la profesionalidad." ${ }^{23}$ En otras palabras cuando hay un compromiso real con lo que se hace la formación como perfeccionamiento del hacer se convierte en una necesidad. De ahí que una vocación puede comenzar como un simple oficio, pero si ese oficio esta antecedido por una vocación la profesionalización tendrá que aparecer en quien realiza el oficio. Menéndez así lo plantea en su libro: "Profesión es una capacidad cualificada, requerida por el bien común, con peculiares posibilidades económicas sociales." ${ }^{24}$

Una de las principales características del mundo contemporáneo ha sido su tecnificación, acelerada de

\footnotetext{
${ }^{22}$ Haldane, John. Vocación y profesión. Encontrar el sentido en el trabajo. En: Revista Empresa y Humanismo Vol. XI, 1/08, p, 155.

${ }^{23}$ González Vila, Teófilo. Vocación, profesión y profesionalidad. En: acontecimiento, p, 49.

${ }^{24}$ Menéndez, Aquiles. Ética profesional. Herrero hermanos: México D.F. 2003, p, 20.
} 
forma exponencial en los últimos años, los procesos que hacen parte de la cotidianidad humana, cada vez requieren mayores niveles de conocimiento y por ende de formación. De ahí que cada vez se necesita mayor mano de obra calificada y las personas deben seguir procesos de cualificación y lo que anteriormente se aprendía como un simple oficio ahora se aprende como una profesión. Fernández así lo indica en su texto: “Una profesión es, ante todo, un servicio a la sociedad único, definitivo y esencial. Único en cuanto los profesionales de una profesión reclaman para sí mismos el derecho exclusivo de realizar las tareas propias de la profesión (aplicar leyes, recetar, etc.), rechazando y persiguiendo el intrusionismo". ${ }^{25}$

Por otra parte en el nacimiento de lo que hoy llamamos profesiones, a mediados de la edad media, sólo se reconocían como tales: el sacerdocio, la medicina y el derecho. Las tres; exigían una vocación ya que no todas las personas eran llamadas a ejercerlas, únicamente las escogidas reflejando una filosofía y cultura propias de la época. Tenían de algún modo un carácter sagrado, en la medida en que se dedicaban a intereses tan elevados como el cuidado del alma, del cuerpo o de lo público, exigiendo por lo tanto que los nuevos miembros hicieran un juramento al ingresar, puesto que la actividad a la que pretendían dedicarse, venía configurada por reglas y valores morales.

Por ejemplo en la mitología griega tenemos el caso de Asclepio, dios de la medicina, quien pierde la vida a causa de un rayo que le envió Zeus como castigo por resucitar a los muertos y son sus hijas Yaso, Higia y Panacea las que siguen con este conocimiento. Garduño así lo señala en su texto: "el concepto de profesión tiene claros orígenes religiosos al establecer cómo se constituyen grupos que regulan el orden social y conferirle un doble sentido: de vocación y misión; que le imprime un carácter ético y religioso a su constitución”26
En un sentido histórico los oficios se han ido perfeccionando con el paso de los años, algunos simplemente han mutado otros han desaparecido, el hecho es que hoy la mayoría de los oficios los denominamos profesiones porque requieren de una serie de conocimientos teóricos y habilidades prácticas para poderlos desarrollar a satisfacción. Hernández así lo presenta en su texto: "Comúnmente se ha llamado profesión a cualquier ocupación que, a través del ejercicio de un conjunto de conocimientos teóricos y prácticos, satisfaga necesidades o requerimientos específicos de una sociedad, favoreciendo el desarrollo de la educación y el desempeño de sus miembros." ${ }^{27} \mathrm{De}$ este modo, si la sociedad se trasforma, se trasforman sus necesidades, por ende, se trasforman sus profesiones.

Hay que tener en cuenta que estas trasformaciones tienen implícitas unas consecuencias que son visibles tanto en el plano personal como en el social. A nivel personal identificamos dichas trasformaciones dependiendo de la época y de las necesidades hay profesiones que comienzan a caer en desuso y otras tienen una total vigencia; mientras que en el plano social los procesos de formación se van trasformando en relación a las necesidades sociales. Se forman los profesionales según las necesidades que tenga la sociedad. Nava Galván nos trae la siguiente reflexión "La profesionalización, es un proceso social complejo; proviene del latín professio; significa profesar, es decir, ejercer una ciencia o un arte de forma voluntaria; se refiere también a una ideología o actividad asociada que se encuentra en diversos grupos de profesionales en los que sus integrantes aspiran a un estatus social." ${ }^{28}$

Por todo lo anterior podríamos decir que esta es la sociedad de la profesionalización de los oficios, si cada vez tenemos problemas más complejos esto quiero decir que necesitamos personas mejor preparadas, esto para nuestra sociedad es sumamente claro. Los procesos de cualificación de las personas cada vez son más largos

\footnotetext{
${ }^{25}$ Fernández Fernández, José Luis. Ética de las profesiones. Madrid, editorial sal terrae, 1993, p, 26.

${ }^{26}$ Garduño G, Silva G. (Compiladores). Antología, Teoría Sociológica Clásica Max Weber, 1998, México. UNAM.

${ }^{27}$ Hernández Escobar, Claudia; Hernández Camarena, Julio; González González, Luis. formación en ética y profesionalismo para las nuevas generaciones de médicos. En: Persona y bioética, Vol, 14, No 1, p, 31

${ }^{28}$ Nava Galán, María Guadalupe. Profesionalización, vocación y ética de enfermería. En: enfermería neurológica, Vol 11, No. 2, $2012,62$.
} 
y más exigentes no solo en el plano de la formación teórica esto también llega al adiestramiento de la parte práctica. Pero pareciera ser que entre más se preocupa la sociedad por la formación teórica práctica de sus personas cada vez olvida más la dimensión vocacional. Y hoy vemos profesionales muy bien preparados pero con una falta de vocación total por lo que hacen. Cortis así lo expresa: "Ya que la vocación sin profesión hace frecuentemente ineficaz y perjudicial la acción educativa, al encontrarse el educador entre la ilusión, el deseo de hacer y la ignorancia de no saber hacer." ${ }^{29}$

\section{El problema de la vocación en el mundo contemporáneo}

Son varios los imperativos en el mundo contemporáneo, hoy se le pide a las personas que deben ser exitosas, comenzando desde la parte económica; también se debe ser eficiente, el tiempo es dinero es una de las principales premisas del capitalismo, esto sumado a una cultura hedonista que nos acompaña desde hace de un par de décadas y la proliferación de las éticas civiles es el marco desde el cual partimos para realizar el análisis de la vocación en el mundo contemporáneo.

Por lo tanto son muchas las contradicciones que encontramos en nuestra sociedad, le pedimos a los jóvenes que sean exitosos rápidamente, pero criticamos en ellos su falta de lealtad con las empresas, promovemos la cultura del hedonismo pero señalamos la falta de compromiso y responsabilidad por parte de las personas, promovemos la autonomía como principio ético y después criticamos la diversidad de posturas y opciones. En muchos aspectos fundamentales somos una sociedad en transición, de ahí que construir acuerdos para estas diferencias se ha convertido en una necesidad de nuestra cultura. Tal como lo señala Bech: "Vivimos en la sociedad del riesgo"30

Quizás esta sea una de las épocas de mayor incertidumbre moral, los cambios de comportamientos no solo entre generaciones, sino entre miembros de la misma generación es un asunto cada vez más visible. Los referentes comunes son cada vez más escasos y los ideales compartidos son cada vez menos compartidos, quienes más sienten esta situación son las personas jóvenes, quienes en muchas ocasiones deben tomar decisiones son un buen apoyo por parte de la sociedad. Marcuschamer nos comparte la siguiente reflexión: "Cuando impera la confusión, los jóvenes postergan su entrada a la universidad debido a la incapacidad de pensar en el futuro, y muchos de los que ingresan eligen las carreras de moda, las más demandadas." ${ }^{31}$

Ya hablábamos de la soledad de los estudiantes en este proceso de elección de una profesión, las pruebas psicológicas lo que muestran son las aptitudes que una persona tiene y como estas aptitudes se acomodan a un perfil profesional, pero dichas pruebas no deberían ser el único factor para que un joven decida algo tan importante como la parte vocacional. Hay otros factores que se identifican como el estatus de la profesión, el reconocimiento social, la presión familiar y la parte económica, sin embargo dichos factores tampoco deberían ser los más determinantes para escoger una profesión. Cuando se indaga por las razones que llevaron a un estudiante a equivocarse en la elección de la carrera casi siempre aparecen estas en primer orden.

Del mismo modo es importante considerar no solo las aptitudes que tengo, sino las expectativas, deseos y por supuesto las debilidades, aunque estas últimas no son factor excluyente a la hora de elegir una profesión. Del mismo modo es fundamental conocer el perfil del estudiante que tiene cada profesión.

\section{Hacia una vocación integral}

Son muchos los retos que enfrentamos en la sociedad actual, los procesos de secularización, especialmente en países como el nuestro, donde ese paso de las sociedades heterónomas a las sociedades autónomas ha traído en muchos temas un gran desconcierto, nos encontramos en una sociedad que avanza a pasos

\footnotetext{
${ }^{29}$ Corts Giner, Isabel. Educar: un arte, una ciencia... una vocación. En: escuela abierta, 5 (2002), p. 91.

${ }^{30}$ Beck, Ulrich. La sociedad del riesgo. Barcelona, Paidos. 1998.

${ }^{31}$ Marcuschamer, Eva. La posmodernidad, cultura y vocación. Volumen 10, Núm. 41, octubre-diciembre, 2008 251. P, 251.
} 
vertiginosos y con poca capacidad de reflexión; otro de los retos que enfrentamos es el fortalecimiento de los modelos democráticos bajo la egida de los derechos humanos y su inquebrantable búsqueda de la justicia y muy especialmente de la equidad de forma tal que los ciudadanos tengan acceso a esos derechos en una sociedad incluyente y pluralista; del mismo modo en términos educativos los retos están a la orden del día, ¿cómo educamos hombres para la sociedad del mañana? Personas comprometidas con el entorno, conscientes de la condición simbiótica que tenemos con la naturaleza, del reto ético que supone la convivencia con otras personas que pueden tener comportamientos, valores e incluso principios diferentes a los que nosotros tenemos.

Todos estos retos deben ser recogidos por las instituciones de nuestra sociedad, especialmente por la institución educativa, esta deberá formar a los hombres del mañana, seres humanos capaces de enfrentar los problemas que plantea esa misma sociedad, en esa búsqueda inagotable de una mejor calidad de vida para nosotros y para los nuestros, surgen infinidad de situaciones que tenemos que mejorar, algunas veces con creatividad, con imaginación y siempre con el mejor ánimo y la mejor disposición. Para lograr esto tendremos que implementar muchas estrategias, pero todo esto sin lugar a dudas comienza con un amor infinito por lo que hacemos, como lo mencionábamos con anterioridad, con una gran vocación, con una capacidad de trasformación acorde a las nuevas necesidades. Malishev así lo señala: "el hombre conserva, en los límites de su existencia individual, su independencia interna en relación con ese mundo circundante, ya que por su propia actividad es capaz de crear y recrear el contenido de las circunstancias que le rodean"32

Quizás esas grandes trasformaciones que necesitamos en lo social comienzan con pequeños cambios en lo particular, debemos mirar en nosotros mismos, quizás allí se encuentran las respuestas a lo universal. Esta invitación no solo recoge la importancia de aquello que pensamos, sino de aquello que sentimos. Detengámonos un momento para pensar en la grandeza a la que podemos aspirar. Adela Cortina así no lo señala: "Obrar racionalmente significa, en principio, saber deliberar bien antes de tomar una decisión con objeto de realizar la elección más adecuada y actuar según lo que hayamos elegido. Quien no reflexiona antes de actuar sobre los distintos cursos de acción y sus resultados, quien no calibra cuál de ellos es más conveniente y quien, por último, actúa en contra de la decisión que él mismo reflexivamente ha tomado, no obra racionalmente." ${ }^{33}$ Antes de elegir una profesión, detengámonos a pensar por un momento considerando todo lo que hemos señalado con anterioridad, que cuando elegimos una profesión lo que elegimos en un estilo de vida, estilo que me debe procurar un servicio al otro y a los otros y nosotros una vida feliz.

\section{Referencias}

Beck, Ulrich. La sociedad del riesgo. Barcelona, Paidos. 1998

Casas, María de la Luz. Conocer y amar: vocación médica. En: cuadernos de bioética. 1998/2 p, 336.

Contreras Mesa, Beatriz. La vocación pedagógica. En: UCMaule - Revista Académica N³9 - Diciembre 2010, p, 144.

Cortina, Adela. Ética de la empresa. Claves para una nueva cultura empresarial. Trotta: Madrid, 2008, p, 18.
Corts Giner, Isabel. Educar: un arte, una ciencia... una vocación. En: escuela abierta, 5 (2002), p. 91.

Fernández Fernández, José Luis. Ética de las profesiones. Madrid, editorial sal terrae, 1993, p, 26.

Ferrari Nieto, Enrique. Circunstancia y vocación: apuntes de ortega para una biografía. En: anuario filosófico, XLII, 2009, P, 607 .

\footnotetext{
${ }^{32}$ Malischev, Mijail, Herrera González, Julián. José Ortega y Gasset: La metafísica existencial de la vida En: eidos nº 12 (2010) págs. 219.

${ }^{33}$ Cortina, Adela. Ética de la empresa. Claves para una nueva cultura empresarial. Trotta: Madrid, 2008, p, 18.
} 
Ferrari Nieto, Enrique. El recorrido de la analogía metafísica del actor en la comprensión de Ortega de la vida como tarea. En: Revista Internacional de Filosofía, vol. XVIII (2013), pp. 319-337

Garduño G, Silva G. (Compiladores). Antología, Teoría Sociológica Clásica Max Weber, 1998, México. UNAM.

Garza Almanza, Victoriano. Vocación profesional. En: cultura científica y tecnológica. Enero- febrero, 2007, año, 4. No, 18. $P, 44$.

González Vila, Teófilo. Vocación, profesión y profesionalidad. En: acontecimiento: Órgano de expresión del Instituto Emmanuel Munier, No 54, 2000, p, 49 - 53.

Gracia, Diego. La vocación docente. En: anuario jurídico y económico escurialense. XL, 2007, P, 810.

Haldane, John. Vocación y profesión. Encontrar el sentido en el trabajo. En: Revista Empresa y Humanismo Vol. XI, 1/08, $p, 155$.

Hernández Escobar, Claudia; Hernández Camarena, Julio; González González, Luis. Formación en ética y profesionalismo para las nuevas generaciones de médicos. En: Persona y bioética, Vol, 14, No 1, p, 31.

Malishev, Mijail, Herrera González, Julián. José Ortega y Gasset: La metafísica existencial de la vida En: eidos $n^{\circ} 12$ (2010) págs. 219.

Marcuschamer, Eva. La posmodernidad, cultura y vocación. Volumen 10, Núm. 41, octubre-diciembre, 2008 251. P, 251.

Marias, Julián, Antropología metafísica. Madrid: Revista de Occidente, 1970, p. 299.

Martínez Casanovas, Carlos. La vocación de ser médico. En: revista de la semg, No. 64, 2004, p, 318.
Marriner Tomey, Ann. Raile Alligood, Martha. Modelos y teorías en enfermería. Elsevier Mosby, Madrid, 2007, p, 74

Menéndez, Aquiles. Ética profesional. Herrero hermanos: México D.F. 2003, p, 20.

Mujica, Jorge Enrique. La vocación de la mujer según Edith Stein

Nava Galán, Ma. Guadalupe. Profesionalización, vocación y ética de enfermería. En: enfermería neurológica, Vol 11, No. 2, 2012, 62 .

Ortega y Gasset, J. el hombre a la defensiva. Obras Completas II, alianza editorial, Madrid, 1983, p, 655 - 656.

Pantoja, Cecilia. En torno al concepto de vocación. En: educación y ciencia. Vol. 2, No, 6. P, 17.

Savater, Fernando. El valor de elegir. Barcelona: Ariel, 2003, $p, 13$.

Vásquez Alonso, Ángel; Manassero Mas, María Antonia. La vocación científica y tecnológica: predictores actitudinales significativos. En: Rev. Eureka Enseñ. Divul. Cien., 2009, 6(2), pp. 214.

Zaragueta, Juan. La vocación profesional. En:

http://www.google.com.co/url? sa $=t \& r c t=j \&-$ $q=\&$ esrc $=$ s\&source $=$ web\& $c d=2$ \&ved $=0 C C I Q F-$ $j A B \& u r l=h t t p \% 3 A \% 2 F \% 2 F w w w . e u s k o m e d i a . o r-$ g\%2FPDFAnlt\%2Fcongresos\%2F04\%2F04040054. pdferei=LklVPiuBPSOsQS_8YKQBgéusg=AFQjCNGknQ93WEIx3NOeFTQA6TgkBlQdw\&bvm $=b v .76247554, d$. eXY tomado 25 de septiembre de 2014. 